\title{
PRAKTIKALITAS SISTEM INFORMASI PENERIMAAN SISWA BARU (PSB) BERBASIS WEB ( Studi Kasus SMK Negeri 7 Padang )
}

\author{
Yuliawati Yunus ${ }^{1}$, Indah Rahmatika Sari ${ }^{2}$ \\ ${ }^{1,2}$ Universitas Putra Indonesia 'Yptk' Padang, Indonesia \\ E-mail: yuliawati_yunus@upiyptk.ac.id,indahrahmah81@gmail.com
}

\begin{abstract}
Abstrak
Penelitian dan pengembangan ini diangkat dari dasar masalah pendaftaran siswa baru yang masih menggunakan teknik manual (menggunkan buku tulis) sehingga kurang efektif dan banyak juga siswa yang berasal dari daerah luar kota Padang. Penelitian inibertujuan untuk mengetahui Praktikalitas Perancangan dan Pembuatan Sistem Informasi Penerimaan Siswa Baru (PSB) Berbasis Web SMK Negeri 7 Padang.Penelitian ini menggunakan metode pengembangan (Research \& Development) 4D. Subjek penelitian berjumlah 21 orang,dengan desain dan langkah-langkah pengembangannya adalah sebagai berikut.(1) Define, pada langkah define akan dilakukan analisis kebutuhan terhadap sistem yang akan kita buat (2) Design, pada langkah ini dilakukan perancangan tehadap sistem akan dibuat (3) Develop, pada langkah ini akan dilakukan tahap penilaian terhadap sistem yang dibuat dan (4) Disseminate, pada tahap ini dilakukan penyebaran produk yang telah dibuat. Pengujian Praktikalitas dilakukan pada sistem Informasi Penerimaan Siswa Baru (PSB) Berbasis Web SMK Negeri 7 yang sudah Valid. Hasil penilaian uji praktikalitas secara keseluruhan penilaian praktikalitas terhadap sistem Informasi Penerimaan Siswa Baru (PSB) Berbasis Web SMK Negeri 7 sebesar 86,26\%, sehingga tingkat kepraktisan/praktikalitas dapat di kategorikan sangat praktis diimplementasikan. Kesimpulannya, berdasarkan penilaian beserta masukan ahli serta hasil dari uji coba lapangan sistem Informasi Penerimaan Siswa Baru (PSB) Berbasis Web sebagai sistem informasi sudah teruji kelayakan, keunggulan, dan dapat digunakan pada proses penerimaan siswa baru SMK NEGERI 7 Padang.
\end{abstract}

Kata kunci: Mobile Web, Penerimaan Siswa, Sistem Informasi

\begin{abstract}
This research and development is motivated by the problem of registering new students conducted manually so that, it is less effective and there are also many students who come from areas outside the city of Padang. This study aims to determine the Practicality of Designing and Making Information Systems for New Student Admissions Based on Mobile Web of SMK Negeri 7 Padang. This research uses a 4D Research \& Development method. The subjects of the study amounted to 21 people, with the design and development steps as follows. (1) Define, in the define step an analysis of the requirements of the system will be carried out (2) Design, in this step a design will be made for the system to be created ( 3 ) Develop, in this step an assessment phase of the system will be made and (4) Disseminate, at this stage the product distribution has been made. Practicality testing is carried out on the Information System for New Student Admissions Based on the Valid Mobile of SMK Negeri 7 Padang. The overall practicality assessment results of the practical assessment of the New Student Admissions Information System Based on SMK Negeri 7 PadangMobile Web is $86.26 \%$, so the practical level can be interpreted to be very practical to use. In conclusion, based on the assessment along with expert input as well as the results of the field trial of the New Student Admissions Information System Based on Mobile Web as an information system that has been tested for its feasibility, excellence, and can be used in the admission process of SMK Negeri 7 Padang.
\end{abstract}

Key word: Mobile Web, Student Admission, information System

$\begin{array}{ll}\text { Dikirim } & : 2019-03-12 \\ \text { Diterima } & : 2019-04-01 \\ \text { Diterbitkan } & : 2019-04-04 \\ \text { DOI : https://doi.org/10.29165/komtekinfo.v5i2 }\end{array}$




\section{Pendahuluan}

Pada era Revolusi 4.0 Perkembangan teknologi yang begitu cepatnya mengharuskan sekolah meningkatkan sarana dan prasarana pendidikan dengan mengikuti perkembangan yang ada untuk mendukung kualitas pendidikan yang lebih baik, seperti yang disebutkan pada pembukaan UUD 1945 "mencerdaskan kehidupan bangsa". Mengenalkan dan mendekatkan sekolah kepada masyarakat, sebenarnya sekolah hendaknya mempromosikan sekolahan mereka kepada masyarakat khususnya bagi siswa yang ingin melanjutkan sekolah ke SMK NEGERI 7 Padang.

SMK Negeri 7 Padang ini merupakan sekolah seni pertunjukan satu-satunya di wilayah Sumatra Barat dan mempunyai siswa yang tidak hanya berasal dari Padang tetapi juga banyak dari daerah lain yang jaraknya lumayan jauh dari Kota Padang. Sehingga dengan adanya sistem informasi ini akan memudahkan calon siswa dalam melakukan pendaftaran tanpa harus pergi ke Padang . Selama ini pendaftaran siswa baru di SMK NEGERI 7 Padang dilakukan secara manual sehingga kurang efektif. Dari pihak sekolah pun akan kesulitan dalam menginputkan data siswa dari manual kedalam komputer, bahkan pegawai tata usaha dalam mengolah data siswa pun nantinya akan kesulitan dan membutuhkan waktu yang cukup lama dalam mengelolanya.

Berdasarkan masalah pendaftaran yang terjadi di SMK NEGERI 7 Padang maka penting dilakukan penelitian dengan judul "Praktikalitas Sistem Informasi Penerimaan Siswa Baru (PSB) Berbasis Web SMK NEGERI 7 Padang”. Adanya sistem informasi berbasis web ini diharapkan meminimalisir kekurangan yang ada di SMK NEGERI 7 Padang ini dan memudahkan semua orang yang mendaftar menjadi siswa baru di SMK NEGERI 7 Padang dan juga akan memudahkan pihak sekolah dalam mengelola data siswa baru. Adapun identifikasi masalah pada permasalahan penelitian ini adalah kurangnya teknologi informasi di SMK NEGERI 7 Padang yang mendukung kegiatan penerimaan siswa baru, Banyaknya siswa berasal dari luar Kota Padang, Sistem pendaftaran yang masih manual, Membutuhkan waktu yang lama dalam mengelola data siswa baru, Pendaftaran siswa baru dilakukan secara online berbasis web, servernya berada di dinas Pendidikan Provinsi Sumbar.

Berdasarkan identifikasi masalah tersebut, maka perlu fokus dalam penelitian ini agar tidak menyimpang dari tujuan yang ingin dicapai dan pemberian solusi terhadap masalah-masalah yang telah teridentitifikasi diatas, yang mana penulis hanya melakukan fokus penelitian untuk Perancangan dan Pembuatan Sistem Informasi Penerimaan Siswa Baru Berbasis (PSB) berbasis web di SMK NEGERI 7 Padang dan mengetahui Praktikalitas Sistem Informasi Penerimaan Siswa Baru (PSB) Berbasis Web di SMK NEGERI 7 Padang.

\section{Tinjauan Literatur}

\subsection{Sistem Informasi}

Sistem informasi merupakan gabungan dari unsur kegiatan kerja yang terstruktur baik informasi, user dan peralatan teknologi informasi yang bersinergi untuk mencapai tujuan dari sebuah sistem yang terstruktur[5]. Selain itu, Sistem informasi merupakan komponen dari empat pilar. Keempat bagian itu software, hardware, infrastruktur dan skill manusia yang terlatih dalam sistem, dalam sebuah sistem informasi keseimbangan antara yang dibutuhkan oleh keadaan nyata dituangkan kedalam sistem [1]. 


\subsection{Mobile Web}

Teknologi mobile atau biasa disebut teknologi komunikasi seluler (Mobile Communication) saat ini merupakan teknologi yang berkembang dengan sangat cepat begitu juga minat penggunaannya bagi masyarakat dunia. Teknologi mobile ini memberikan fasilitas komunikasi dan pertukaran data yang cepat dan mudah serta bisa dilakukan bebas dimapun dan kapanpun[3]. website juga dapat diartikan sebagai kumpulan halaman yang berisi informasi data digital baik berupa teks, gambar, animasi, suara dan video atau gabungan dari semuanyayang disediakan melalui jalur koneksi internet sehingga dapat diakses dan dilihat oleh semua oramg diseluruh dunia[1]. Web mobile menurut (http://en.m.wikipedia.org) juga dikenal sebagai mobile internet, mengacu pada browser berbasis internet layanan yang di akses dari handled perangkat mobile, seperti smartphone atau fitur ponsel, melalui ponsel atau lainnya. Adapun Responsive Web Design (RWD) adalah sistem ewe yang menggunakan metode yang membawa usernya berada pada kemudahan dalam menggunakan sistem dengan berbagai peralatan, baik laptop, notebook bahkan smartphone.

\subsection{Php MySQL}

MySQL merupakan platform DBMS yang sering digunakan oleh programmer aplikasi web. Sublime text adalah editor untuk pengkodean dan integrasi teks yang dapat multiplatform operating system memanfaatkan teknologi Phyton API [7]. Sedangkan, PHP (Hypertext Preprocessor) merupakan bahasa pemograman yang digunakan untuk pembuatan aplikasi web yang berguna untuk pengelolaan data dan informasi berkelanjutan[4].

\section{Metodologi}

\subsection{Jenis Penelitian}

Penelitian ini menggunakan jenis penelitian dan pengembangan atau biasa disebut dengan $R \& D$ (research and development),yaitu metode penelitian yang digunakan pada jenis ini untuk melahirkan produk, alat dan perangkat tertentu, dan menguji kemudahan/praktikalitas produk tersebut. Model pengembangan dalam penelitian ini menggunakan model 4D Model ini dikembangkan oleh S. Thiagarajan (1974). Model 4D merupakan singkatan dari Tahapa berikut; Define (Pendefenisian masalah), Design (Perancangan Produk), Development and Dissemination (Pengembangan dan Penyebaran produk).

\subsection{Subjek Penelitian}

Subjek yang diambil pada penelitian ini adalah siswa kelas $X$ jurusan musik SMK Negeri 7 Padang berjumlah 20 orang dan 1 orang pegawai tata usaha SMK NEGERI 7 Padang.

\subsection{Jenis Data}

Jenis data yang diambil pada penelitian ini merupakan data primer. Data diperoleh dari pelaksanaan uji coba Pembuatan Sistem Informasi PSB dengan Sistem yang sudah terhubung ke internet. Subjek akan bertindak sebagai siswa yang mendaftar kemudian melakukan penilaian terhadap Sistem Informasi menggunakan Alat Penelitian berupa Angket Uji Praktikalitas.

\subsection{Instrumen Penelitian/ Instrumen Kepraktisan}

Table 1: Kisi-Kisi Angket Praktikalitas

\begin{tabular}{|l|l|l|l|}
\hline No & Indikator & Item & Jumlah \\
\hline
\end{tabular}




\begin{tabular}{|l|l|l|l|}
\hline 1 & Kemudahan pengguna & $1,2,3,4,5$ & 5 \\
\hline 2 & Keberfungsian & $6,7,8,9,10$ & 5 \\
\hline 3 & Manfaat & $11,12,13,14,15$ & 5 \\
\hline 4 & Efektifitas Waktu Penggunaan & 16,17 & 2 \\
\hline 5 & Interpretasi/pemahaman & $18,19,20$ & 3 \\
\hline
\end{tabular}

Sumber : Riza \& Handayani (2014: 125)

Instrumen yang digunakan disusun menurut pola skala dalam bentuk kontiniu kategori dengan lima bobot penilaian dan pernyataan angket bersifat positif.

Tabel 2: Penilaian Jawaban

\begin{tabular}{|l|l|l|}
\hline Pilihan & Keterangan & Bobot \\
\hline Sangat Setuju & SS & 5 \\
\hline Setuju & S & 4 \\
\hline Kurang Setuju & KS & 3 \\
\hline Tidak Setuju & TS & 2 \\
\hline Sangat Tidak Setuju & STS & 1 \\
\hline
\end{tabular}

Sumber : [8]

\subsection{Teknik Analisa Data}

\section{Analisis Uji Praktikalitas sistem informasi penerimaan siswa baru}

Data uji praktikalitas sistem informasi penerimaan siswa baru dianalisis dengan menggunakan rumus yang dimodifikasi dari Purwanto (2010: 102) berikut ini:

$\mathbf{N P}=\mathbf{R} / \mathbf{S M} \times \mathbf{1 0 0}$.

Keterangan :

$\mathrm{NP}=$ Nilai Persen harapan

$\mathrm{R}=$ Nilai Mentah pengisian Angket

$\mathrm{SM}=$ Skor Maksimum

$100=$ Nilai Bilangan yang tetap

Setelah presentase diperoleh, dilakukan pengelompokkan sesuai kriteria yang dirancang oleh Purwanto (2010 : 103) berikut ini :

Tabel 3: Penilaian Praktikalitas

\begin{tabular}{|l|l|l|}
\hline No & Nilai & Aspek Yang Dinilai \\
\hline 1 & $86 \%-100 \%$ & Sangat Praktis \\
\hline 2 & $76 \%-85 \%$ & Praktis \\
\hline 3 & $60 \%-75 \%$ & Cukup Praktis \\
\hline 4 & $55 \%-59 \%$ & Kurang Praktis \\
\hline 5 & $\leq 54 \%$ & Tidak Praktis \\
\hline
\end{tabular}

Sumber : Purwanto $(2010: 103)$

Kemudian menentukan nilai distribusi frekuensi praktikalitas yang dimodifikasi dari Prof. Dr. $\mathrm{H}$. Agus I. Irianto berikut ini:

\section{$\mathbf{R}=$ data tertinggi - data terendah}


$K=1+3.3 \log n$

$\mathbf{P}=\mathbf{R} / \mathbf{K}$

Keterangan :

$\mathrm{P}=$ Panjang untuk Interval Kelas

$\mathrm{R}=$ Hitung jarak atau rentangan

$\mathrm{K}=$ Jumlah kelas

\subsection{Rancangan Interface}

Adapun Rancangan Desain user interface merupakan desain tampilan sistem yang dibuat mulai dari desain input dan desain ouput.

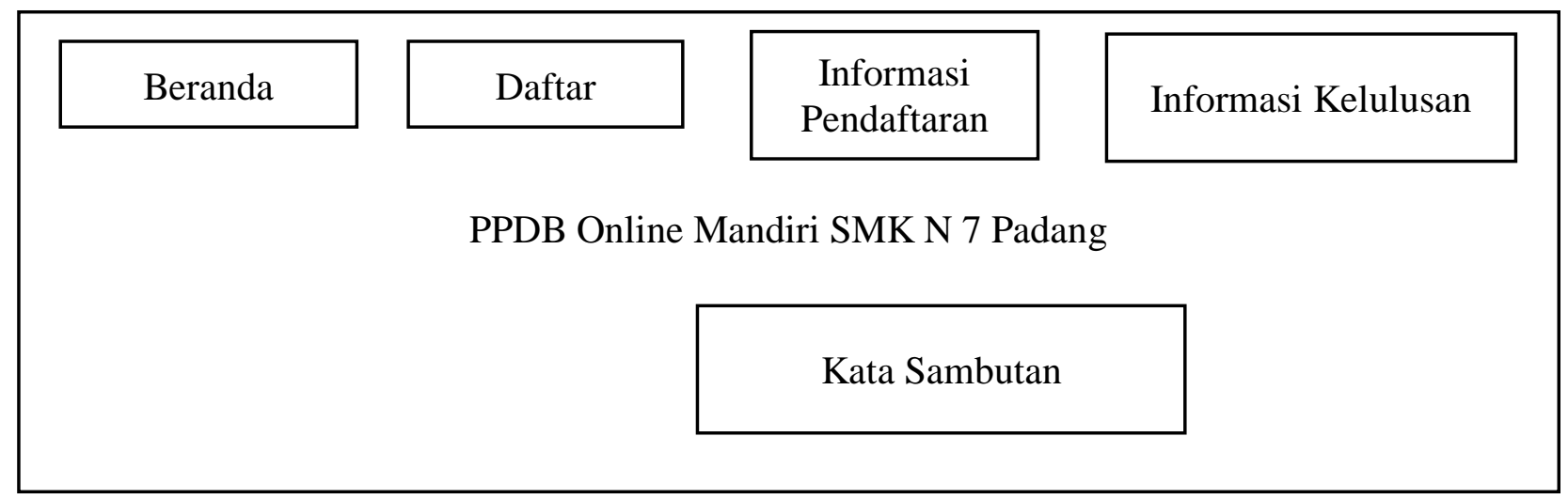

Gambar 1 : Rancangan interface

\section{Hasil dan Diskusi}

\subsection{Hasil Rancangan Tampilan}

Halaman Beranda Home yang mengambarkan tampilan awal saat memasuki sistem pendaftaran siswa baru. Pada home ini di lengkapi dengan menu yang dapat untuk memilih ke halaman yang ingin di tuju bisa kita lihat pada gambar dibawah ini. 

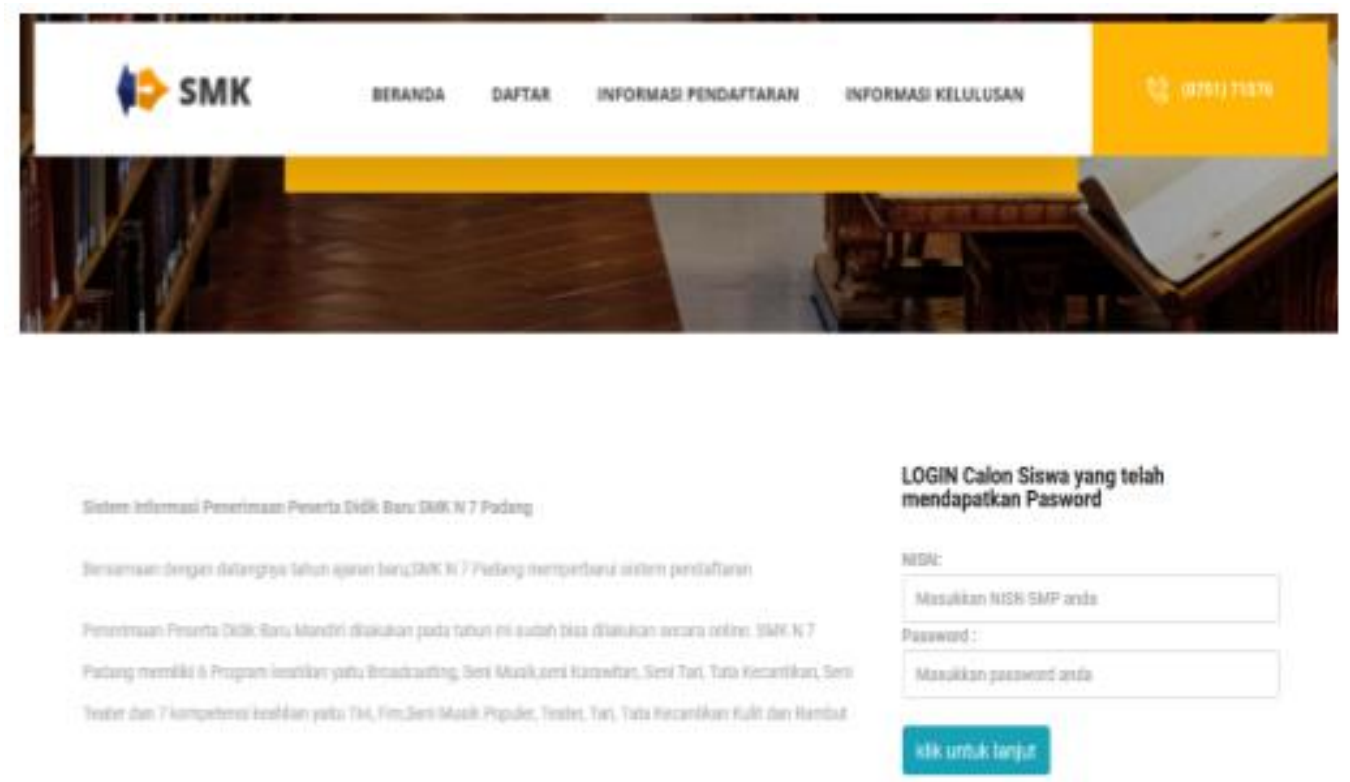

Gambar 2: Halaman Beranda

\subsection{Analisa Data}

Uji Praktikalitas Uji coba praktikalitas yang dilakukan oleh 20 siswa dan 1 pegawai tata usaha untuk sistem informasi penerimaan siswa baru berbasis (PSB) berbasis web yang ditinjau dari aspek (1) efektif : 87,808\%; (2) kreatif: 86,856\% (3) Efisien : 88,382\% (4) interaktif :84,76\% (5) Menarik: $83,49 \%$. Secara keseluruhan penilaian uji praktikalitas terhadap Sistem informasi penerimaan siswa baru berbasi mobile web sebesar $86,26 \%$, sehingga media tersebut bisa dikatakan sangat praktis digunakan calon siswa dan pegawai tata usaha untuk penerimaan siswa baru. Untuk sebaran datanya dapat dilihat pada tabel 4.

Tabel 4: Distribusi Frekuensi Skor Angket Praktikalitas

\begin{tabular}{|c|c|c|c|}
\hline No & $\begin{array}{c}\text { Kelas - } \\
\text { Interval }\end{array}$ & F0 & \%F0 \\
\hline 1 & $78-80$ & 4 & 19.05 \\
\hline 2 & $81-83$ & 1 & 4.76 \\
\hline 3 & $84-86$ & 5 & 23.81 \\
\hline 4 & $87-89$ & 3 & 14.29 \\
\hline 5 & $90-92$ & 5 & 23.81 \\
\hline 6 & $93-95$ & 3 & 14.29 \\
\hline & Jumlah & $\mathbf{2 1}$ & $\mathbf{1 0 0}$ \\
\hline
\end{tabular}

Sumber: Pengolahan Data Mandiri

Berdasarkan pada tabel tersebut dapat dijelaskan untuk mencari perhitungan interval kelas dan panjang kelas. 


\section{Angket Praktikalitas}

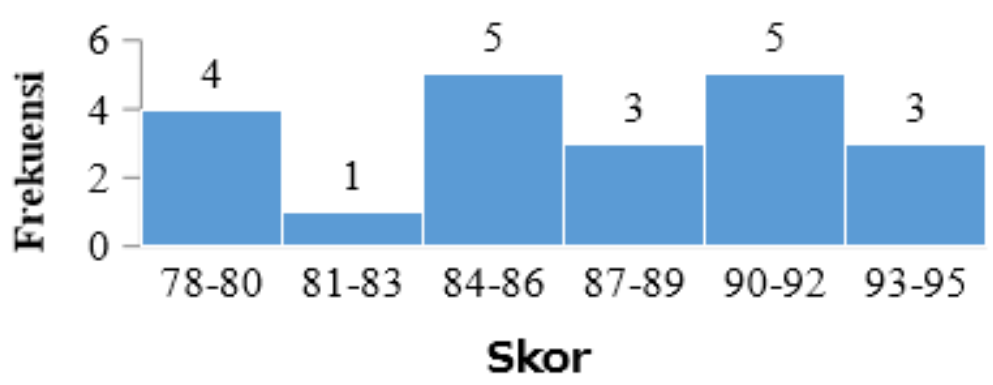

Gambar 4: Histogram Angket Praktikalitas

\subsection{Pembahasan}

Perancangan dan pembuatan sisten informasi penerimaan siswa baru (PSB) berbasis web di SMK NEGERI 7 Padang yang telah dibuat, dan berdasarkan penelitian yang dilakukan bahwasanya sistem informasi penerimaan siswa baruyang di uji cobakan kepada siswa dan pegawai tata usaha dalam bentuk uji coba praktikalitas dinyatakan sangat praktis digunakan.

Tabel 5: Hasil uji coba sistem informasi penerimaan siswa baru

\begin{tabular}{|c|c|c|}
\hline $\begin{array}{c}\text { Hasil Uji } \\
\text { Coba }\end{array}$ & Presentase & Keterangan \\
\hline Praktikalitas & $86,26 \%$ & Sangat Praktis \\
\hline
\end{tabular}

\section{Kesimpulan}

Perancangan dan pembuatan Sistem Informasi Penerimaan siswa Baru Berbasis (PSB) berbasis web SMK NEGERI 7 Padang mengikuti jenis penelitian dan pengembangan (Research and Development) [8]. Berdasarkan diskripsi, analisis data, dan pengembangan Sistem Informasi ini dapat disimpulkan bahwasanya hasil uji praktikalitas adalah Sebesar 86,26\%, sehingga tingkat praktikalitasnya dapat di kategorikan Sangat Praktis. Sistem Informasi ini;

a. Harapan dengan sistem ini dapat membantu pihak SMK NEGERI 7 Padang dalam proses penerimaan siswa baru.

b. Bagi peneliti selanjutnya lebih mengembangkan sistem informasi ini menjadi sistem informasi yang lebih sempurna.

c. Prosedur PPDB ini adalah berdasarkanpada pelaksanaan PSB periode terakhir, jadi apabila terjadi perubahan prosedur maka perlu dilakukan perubahan ataupun penyusaian prosedur pada perangkat lunak.

\section{Referensi}

[1] Abdullah,rohi.2018.7 in 1 Pemrograman Web Untuk Pemula.Jakarta:PT Elex Media Komputindo.

[2] Azifah, N., \& Yunus, Y. (2017). PERANCANGAN DAN PEMBUATAN BLOG ANIMATIF MATA PELAJARAN TEKNOLOGI INFORMASI DAN KOMUNIKASI (TIK) KELAS XI (Studi Kasus SMA Baiturrahmah Padang). PENDIDIKAN TEKNOLOGI INFORMASI UPI-YPTK, 4(1). 
[4] Komputer,Wahana.2009.PHPProgramming.Yogyakarta:C.V.Andi Offset.

[5] Kadir,Abdul.2009.Dasar dan Perancangan \& implementasi Database Relasional. Yogyakarta:C.V Andi Offset.

[6] Putra,nusa.2015.Research \& Development Penelitian dan Pengembangan:suatu Pengantar.Jakarta:Rajawali Pers.

[7] Riyanto.2013.Membangun Mobile Web Store dengan Codelgniter, MySQL \& Jquery Mobile.Yogyakarta:CV Andi Offset

[8] Sugiyono.2016.Metode Penelitian Kuantitatif, Kualitatif dan R\&D.Bandung:Alfabeta.

[9] Wijaya, I. (2018). PERANCANGAN DAN PEMBUATAN E-LEARNING BERBASIS MOODLE PADA MATA PELAJARAN KETERAMPILAN KOMPUTER DAN PENGELOLAAN INFORMASI (KKPI). PENDIDIKAN TEKNOLOGI INFORMASI UPI-YPTK, 5(1). 